\title{
Source rupture process of the Papua New Guinea earthquake of July 17, 1998 inferred from teleseismic body waves
}

\author{
Masayuki Kikuchi, Yoshiko Yamanaka, Katsuyuki Abe, and Yuichi Morita \\ Earthquake Research Institute, University of Tokyo, Tokyo 113-0032, Japan
}

(Received June 8, 1999; Revised October 21, 1999; Accepted October 21, 1999)

\begin{abstract}
A large earthquake (Ms 7.1) occurred off northwest coast of Papua New Guinea (PNG), and a massive tsunami attacked villages to cause a devastating damage. In an attempt to ascertain the tsunami source, we investigate the source rupture process using teleseismic data at IRIS network as well as local data at Jayapura, Irian Jaya, station. The source parameters obtained are: $\left(\right.$ strike, dip, slip) $=\left(301^{\circ}, 86^{\circ}, 91^{\circ}\right)$; the seismic moment $=4.3 \times 10^{19} \mathrm{Nm}$ $(M w=7.0)$; the duration of main rupture $=19 \mathrm{~s}$; the centroid depth $=20 \pm 5 \mathrm{~km}$; the extent of rupture along the fault strike $=40 \mathrm{~km}$; the average dislocation $=1.8 \mathrm{~m}$; the stress drop $=7.3 \mathrm{MPa}$. The tsunami magnitude $M t$ determined from tide-gage data at long distance is 7.5, significantly larger than $M s$, so that the PNG earthquake is characterized as a tsunami earthquake. Tsunami earthquakes might have been caused by slow rupture, submarine landslide, and high-angle dip-slip. Our teleseisimic analysis precludes the first two candidates and favors the third one as a source of the present earthquake, although it does not necessarily exclude the possibility of an aseismic landslide induced by the main shock or its aftershocks.
\end{abstract}

\section{Introduction}

In the evening of July 17, 1998, a large earthquake occurred off northwest coast of Papua New Guinea. Associated with this earthquake, a massive tsunami attacked Sissano, west of the town of Aitape in west Sepik. The maximum tsunami height was estimated to be more than 10 meters (Kawata et al., 1999). At least 2,000 people were killed, hundreds injured, and several villages were destroyed completely by tsunami. According to QED information by NEIC, the origin time is $08: 49: 16 \mathrm{UT}$; the epicenter is $2.932^{\circ} \mathrm{S} 141.797^{\circ} \mathrm{E}$; the depth is $10 \mathrm{~km}$; the surface wave magnitude $M s$ is 7.1 . In view of the fact that a typical tsunami height for this earthquake size $(M s 7)$ is as high as a few meters, this event is characterized as a tsunami earthquake in that the observed tsunami was much higher than that expected from the earthquake magnitude.

In an attempt to ascertain the tsunami source, we here investigate the source rupture process of this earthquake using teleseismic body waves. The aftershocks are also examined by using local seismic data at Jayapula, Irian Jaya, where the broadband seismograph (STS-1) had been installed by Earthquake Research Institute, University of Tokyo and began to operate just before the July 17 earthquake. The station is plotted in Fig. 1, together with epicenters of the main shock and aftershocks.

\section{Teleseismic Data Analysis}

We used teleseismic body waves (vertical P and transverse $S$ waves) recorded at 13 stations of IRIS broadband seismograph network. The observation stations are shown in Fig. 2.

Copy right(C) The Society of Geomagnetism and Earth, Planetary and Space Sciences (SGEPSS); The Seismological Society of Japan; The Volcanological Society of Japan; The Geodetic Society of Japan; The Japanese Society for Planetary Sciences.
The azimuthal coverage is not very good but still sufficient to resolve some details of the source characteristics. Using QED's epicenter and Jeffreys-Bullen's travel time table, the broadband records were windowed for 2 minutes starting at $5 \mathrm{sec}$ before the arrival time of direct $\mathrm{P}$ or $\mathrm{S}$ wave. They were band-passed between $0.002-1 \mathrm{~Hz}$, and converted to ground displacement with a sampling time of $0.5 \mathrm{~s}$.

We employed an inversion scheme performed by Kikuchi and Kanamori (1995). First, with a point source approximation, we determined the fault mechanism fitting the observed waveforms. Next, fixing the focal mechanism, we constructed a grid scheme putting 5 grid points at every 10 $\mathrm{km}$ along the fault strike (Fig. 1) and 3 grid points at every $5 \mathrm{~km}$ along the dip. Three-layer model ( $4 \mathrm{~km}$ thick ocean, 15 $\mathrm{km}$ thick crust and semi-infinite mantle as given in Table 1) was used as a near-source structure. Model parameters are the moment-rate functions at the individual grid points. The positivity constraint was imposed on the moment-rate function.

The inversion procedure was made individually for two possible fault planes: vertical and horizontal. It turned out that the variance reduction was slightly better in case of vertical fault plane. However the differences in variance reduction are so close that the teleseismic data alone cannot well judge which of the P-wave nodal planes was the actual fault plane. Nevertheless, combining our result with other information such as the relocated aftershock distribution (Hurukawa, 1999), we conclude that the vertical fault plane is preferred to the horizontal fault plane.

The source characteristics such as the mechanism diagram, the moment-rate function and the final moment release along the fault strike are shown in Fig. 3. A small introductory rupture is seen to precede a main rupture by about $10 \mathrm{~s}$. The 


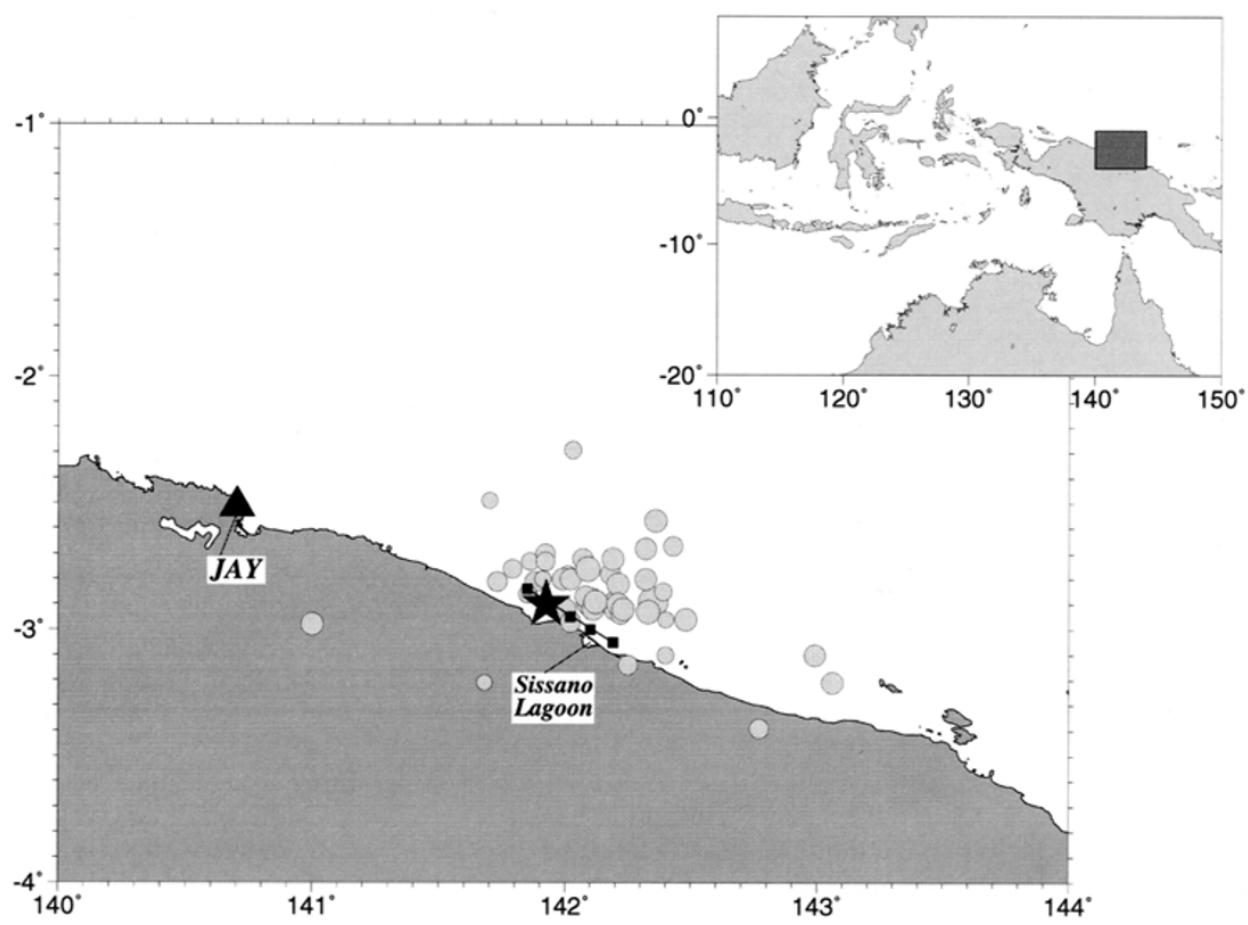

Fig. 1. Distribution of the main shock (star) and the aftershocks (gray circles) due to PDE information by NEIC. The magnitude ( $m b$ ) of the aftershocks ranges from 3.2 to 5.9. JAY (triangle) indicates the broadband seismograph station at Jayapura, Irian Jaya, operated by Earthquake Research Institute, University of Tokyo. Black squares denote grid points along the fault strike used in the waveform inversion.

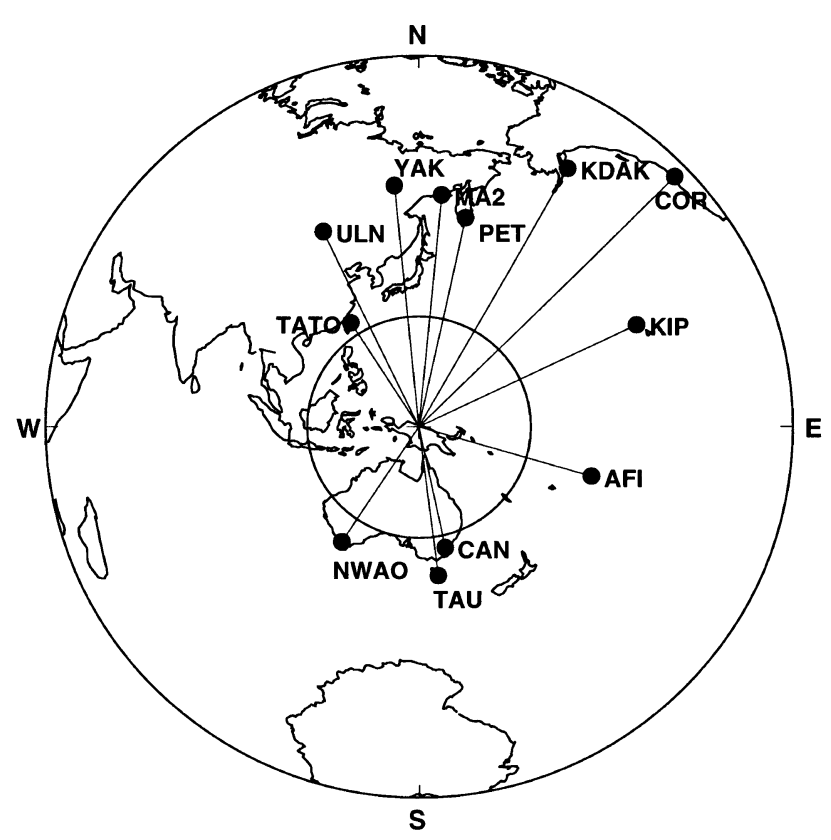

Fig. 2. IRIS broadband seismograph stations used in the present analysis. Map is drawn onto an equal distance projection. The inner and outer circles correspond to the epicentral distances of $30^{\circ}$ and $100^{\circ}$, respectively.

epicenter was relocated to $2.900^{\circ} \mathrm{S}, 141.924^{\circ} \mathrm{E}$, about $15 \mathrm{~km}$ east to the NEIC's. The main rupture initially propagated bilaterally, and then it tended to propagate mainly to the southeast. The extent of rupture is estimated to be about 40 $\mathrm{km}$ in length and $15 \mathrm{~km}$ in width. The rupture front velocity during the main stage is about $2 \mathrm{~km} / \mathrm{s}$. It should be noted (a)

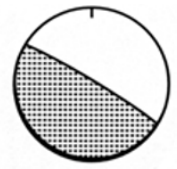

(b) Total moment-rate

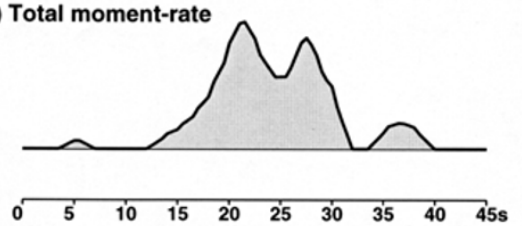

(c)

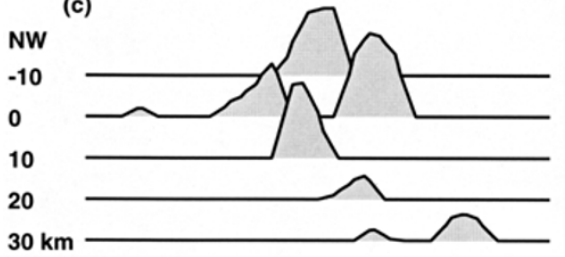

SE

Fig. 3. Results of teleseismic analysis. (a) mechanism solution, (b) total moment-rate function, and (c) moment-rate functions at grid points along the fault strike and final moment release at each fault segment with a spacing of $10 \mathrm{~km}$.

that a delayed rupture was seen near the initial break of the seismic fault.

The source parameters are summarized in Table 2. In calculating the average dislocation, we assumed the rigidity 
Table 1. Near-source structure models used in the waveform inversion.

\begin{tabular}{|c|c|c|c|c|c|c|c|}
\hline \multicolumn{4}{|c|}{ Model for teleseismic data analysis } & \multicolumn{4}{|c|}{ Model for local data analysis } \\
\hline$V p$ & $V s$ & $\rho$ & $D$ & $V p$ & $V s$ & $\rho$ & $D$ \\
\hline 1.50 & 0.00 & 1.00 & 4 & 5.50 & 2.80 & 2.30 & 5 \\
\hline 6.50 & 3.74 & 2.87 & 15 & 6.50 & 3.74 & 2.87 & 10 \\
\hline 7.80 & 4.40 & 3.30 & - & 7.80 & 4.40 & 3.30 & - \\
\hline
\end{tabular}

$V p, V s=\mathrm{P}$-wave and S-wave velocities $[\mathrm{km} / \mathrm{s}]$;

$\rho=$ density $\left[10^{3} \mathrm{~kg} / \mathrm{m}^{3}\right] ; D=$ thickness $[\mathrm{km}]$

Table 2. Source parameters of the main shock.

$$
\begin{aligned}
& \text { origin time }=08: 49: 14 \mathrm{UT} \\
& \text { epicenter }=2.900^{\circ} \mathrm{S}, 141.924^{\circ} \mathrm{E} \\
& \text { (strike, dip, slip) }=\left(301^{\circ}, 86^{\circ}, 91^{\circ}\right) \\
& \text { seismic moment } M o=4.3 \times 10^{19}[\mathrm{Nm}](M w=7.0) \\
& \text { source duration of main rupture }=19[\mathrm{~s}] \\
& \text { centroid depth } H=20 \pm 5[\mathrm{~km}] \\
& \text { fault area } S=40 \times 15\left[\mathrm{~km}^{2}\right] \\
& \text { average dislocation } D=M o / \mu S=1.8[\mathrm{~m}] \\
& \text { stress drop } \Delta \sigma=2.5 \mathrm{Mo} / S^{1.5}=7.3[\mathrm{MPa}]
\end{aligned}
$$

$\mu=40 \mathrm{GPa}$. The focal mechanism (vertical dip-slip) and the total seismic moment $\left(M o=4.3 \times 10^{19} \mathrm{Nm}\right)$ obtained in this paper are consistent with the CMT solutions: $M o=$ $5.2 \times 10^{19} \mathrm{Nm}$ determined by Harvard University and $M o=$ $4.3 \times 10^{19} \mathrm{Nm}$ by U.S. Geological Survey. The stress drop $\Delta \sigma=7.3 \mathrm{MPa}$ which is comparable with a typical value for intra-plate earthquakes (Kanamori and Anderson, 1975). The waveform comparison is shown in Fig. 4.

\section{Tsunami Data at Long Distance}

Based on the empirical relation between the maximum tsunami height $H \mathrm{~m}$ and the moment magnitude $M w$, the tsunami magnitude $M t$ is defined by Abe (1979) as follows:

$$
M t=\log H+B
$$

where $B$ is a constant which depends on the pair of source region and observation region. For the pair of Japan stations and Guam-Mariana events, $B=8.4$.

Tsunami waves associated with the PNG earthquake were observed in Japan, the epicentral distance being about 40 degree. There are 11 data available along the Japan coast. The average tsunami height is $0.13 \pm 0.03 \mathrm{~m}$. Substituting this into (1), we have $M t=7.5$. This $M t$ is significantly larger than $M s$ and $M w$. According to Abe (1989), the difference between $M t$ and $M s, 0.4$, is marginal for classifying this event as the typical "tsunami earthquake."

\section{Broadband Record at JAY}

The broadband seismograph (STS-1) was installed in December, 1997 at Jayapura, Irian Jaya, about $150 \mathrm{~km}$ west

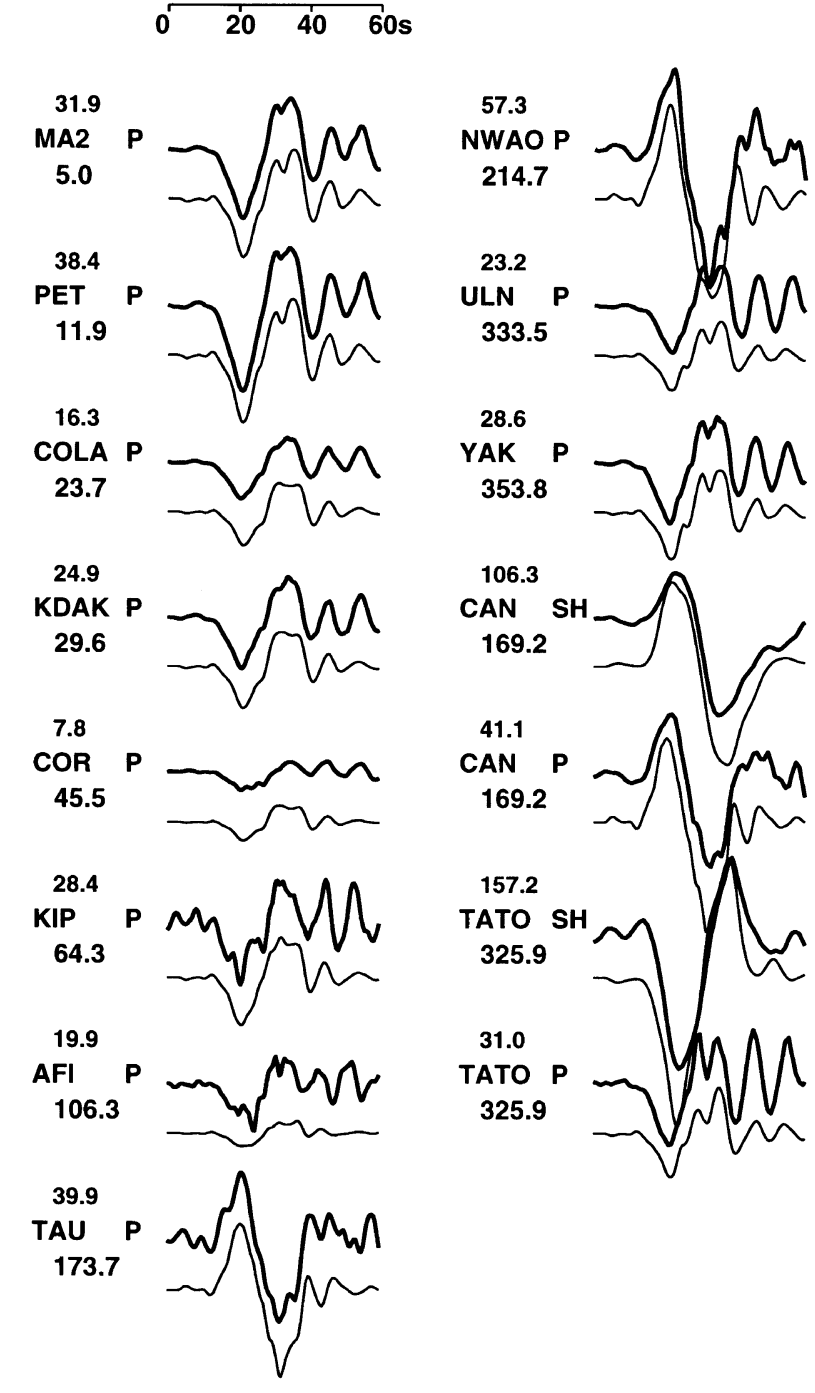

Fig. 4. Comparison of observed waveforms (upper trace) and resultant synthetic waveforms (lower trace). The number above station code indicates peak-to-peak value of the observed displacement record [unit $=$ micro-meter], and the number below the station code is the source-to-station azimuth.

of the epicenter (Fig. 1). This is one of the stations of the Ocean Hemisphere Network (Morita, 1997). Latitude, longitude and altitude are $2.515^{\circ} \mathrm{S}, 140.703^{\circ} \mathrm{E}$ and $439 \mathrm{~m}$, respectively. Continuous record with a sampling rate of $20 \mathrm{~Hz}$ are provided via Magnet-Optical Disk or public telephone. 


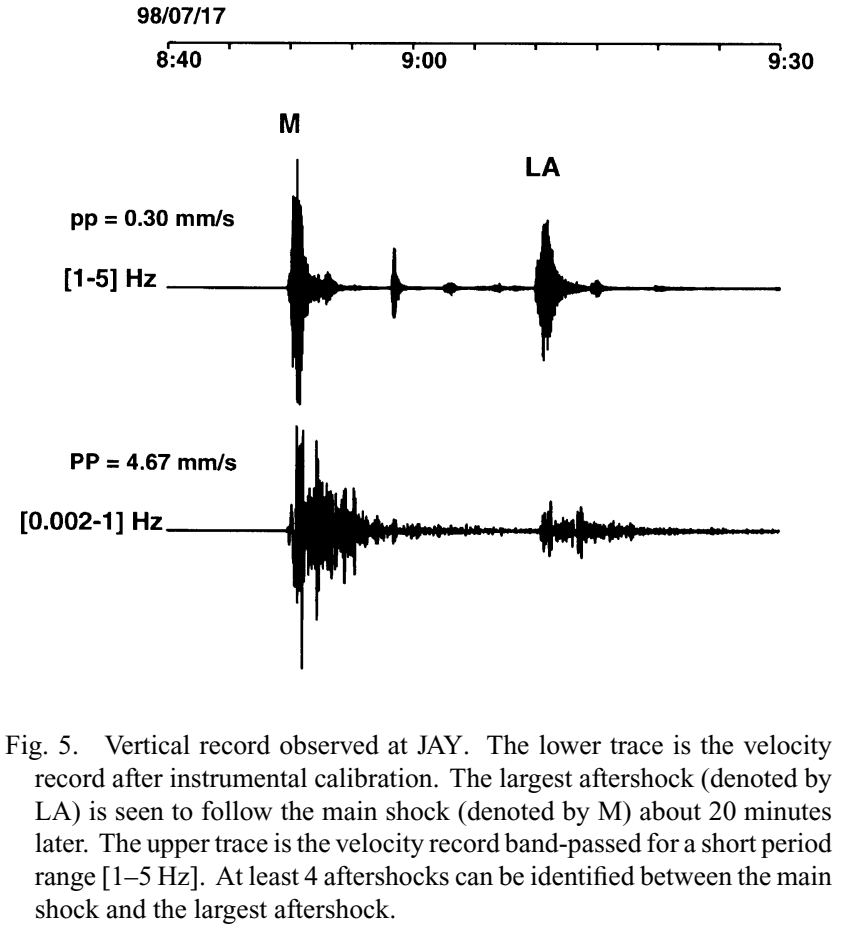

Fig. 5. Vertical record observed at JAY. The lower trace is the velocity record after instrumental calibration. The largest aftershock (denoted by ) is seen to follow the main shock (denoted by M) about 20 minutes range $[1-5 \mathrm{~Hz}]$. At least 4 aftershocks can be identified between the main shock and the largest aftershock.
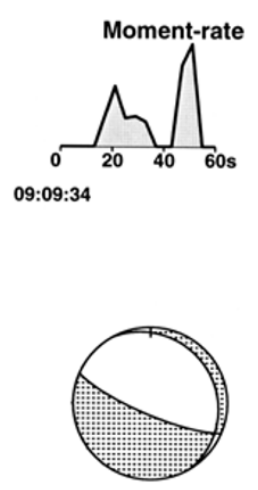

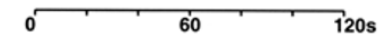

UD
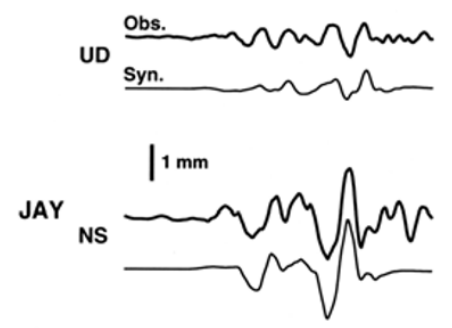

EW

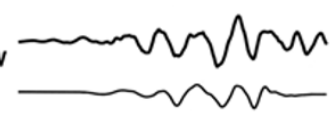

Fig. 6. Mechanism solution and moment-rate function of the largest aftershock obtained from local data (three components of ground displacement) at JAY. The time history is rather complex and the duration is as long as $40 \mathrm{~s}$.

In Fig. 5, lower trace shows the broadband velocity record. It is seen that the main shock is followed by the largest aftershock about 20 minutes later. The maximum amplitude of the aftershock is about $1 / 4$ of that of the main shock, corresponding to the magnitude difference of 0.6. Upper trace in Fig. 5 shows ground velocity band-passed for a short period range $[1-5 \mathrm{~Hz}]$. We can identify at least 4 aftershocks between the main shock and the largest aftershock.

Employing this local data, we examined the focal mechanism and time history of the main shock and the largest aftershock. Discrete wave number method (Bouchon, 1981) was then used to calculate the Green's function for a doublecouple source placed at a horizontal three-layer structure (Table 1). We confirmed that the source characteristics obtained for the main shock basically coincides with the teleseismic
Table 3. Source parameters of the largest aftershock

$$
\begin{aligned}
& \text { origin time }=09: 09: 52 \mathrm{UT} \\
& \text { epicenter }=2.952^{\circ} \mathrm{S}, 142.096^{\circ} \mathrm{E} \\
& (\text { strike, dip, slip })=\left(111^{\circ}, 75^{\circ},-105^{\circ}\right) \\
& \text { seismic moment }=6.5 \times 10^{18}[\mathrm{Nm}](M w=6.5) \\
& \text { source duration }=42[\mathrm{~s}] \\
& \text { centroid depth }=14[\mathrm{~km}]
\end{aligned}
$$

solution given above. The result for the largest aftershock is shown in Fig. 6. The mechanism solution reveals a normal fault which at a glance seems different from a reverse fault obtained for the main shock. Actually the fault geometry of both main shock and aftershock is quite similar except for a slight difference in the fault dip. On the other hand, the time history of the aftershock is more complex and rather longer. It may be regarded as two discrete events whose onset times are separated by $30 \mathrm{~s}$. The main source parameters are given in Table 3.

\section{Discussion}

So far intensive survey for the near-coast submarine topography and aftershock observation have been made in an attempt to examine the tsunami source. But the cause of the massive tsunami has not yet been ascertained definitely. Imamura (1999) made a numerical simulation and proposed a composite model of a submarine landslide and a seismic fault to explain the generation of a local massive tsunami.

There are some possible sources proposed for tsunami earthquakes. One of the typical models is a slow earthquake such as the 1992 Nicaragua earthquake (Kanamori and Kikuchi, 1993) and the 1896 Sanriku tsunami earthquake (Tanioka and Satake, 1996). For ordinary shallow earthquakes, some empirical relations between the source duration $\tau$ and the seismic moment $M o$ have been proposed as follows (Furumoto and Nakanishi, 1983; Ekstrom and Engdahl, 1989):

$$
M o / \tau^{3}=0.25-1 \times 10^{16}\left[\mathrm{Nm} / \mathrm{s}^{3}\right] .
$$

For slow earthquakes, the value of $M o / \tau^{3}$ must be much smaller than the above value. In fact the Nicaragua event gives $M o=3.7 \times 10^{20} \mathrm{Nm}$ and $\tau=110 \mathrm{~s}$ (Kikuchi and Kanamori, 1995), so that $M o / \tau^{3}=2.8 \times 10^{14} \mathrm{Nm} / \mathrm{s}^{3}$. For the present earthquake, the value of $M o / \tau^{3}$ is $0.6 \times 10^{16}$ $\mathrm{Nm} / \mathrm{s}^{3}$, lying well within a range for ordinary earthquakes.

The other typical model for tsunami earthquakes is a submarine landslide near trench as shown for the 1929 Grand Banks earthquake (Hasegawa and Kanamori, 1987). In addition to these models a shallow high-angle dip-slip fault is a possible candidate for tsunami earthquake. Abe (1985) compared tsunamigenic earthquakes with different mechanisms and found that, in case of high-angle dip-slip events, the tsunami magnitude $M t$ determined by (1) is larger than $M w$ by $0.2-0.4$. Hence, the difference between $M t$ and $M w$ observed in the present earthquake can be accounted by our model. Computer simulation for tsunami at long distance 
also suggests that a high-angle dip-slip source with $M w 7.1$ can explain the tide-gage and ocean bottom tsunami records observed at Japan coast (Tanioka, 1998). Thus our teleseismic analysis precludes the possibility of slow earthquake, and favors a high-angle dip-slip source.

Let us next examine the possibility of a submarine landslide. We model it with a single-force at free surface. It is well known that the $\mathrm{P}$-wave radiation pattern having vertical and horizontal nodal planes such as shown in Fig. 3(a) can be explained equally by either a single-force or a double-couple source. On the other hand, the radiation pattern of the radial S-waves can distinguish a double-couple source and a single-force. The azimuthal variation of the wave shape can also distinguish a buried source and a free surface source. A single-force placed at free surface does not accompany a distinct later phase due to free surface reflection, resulting

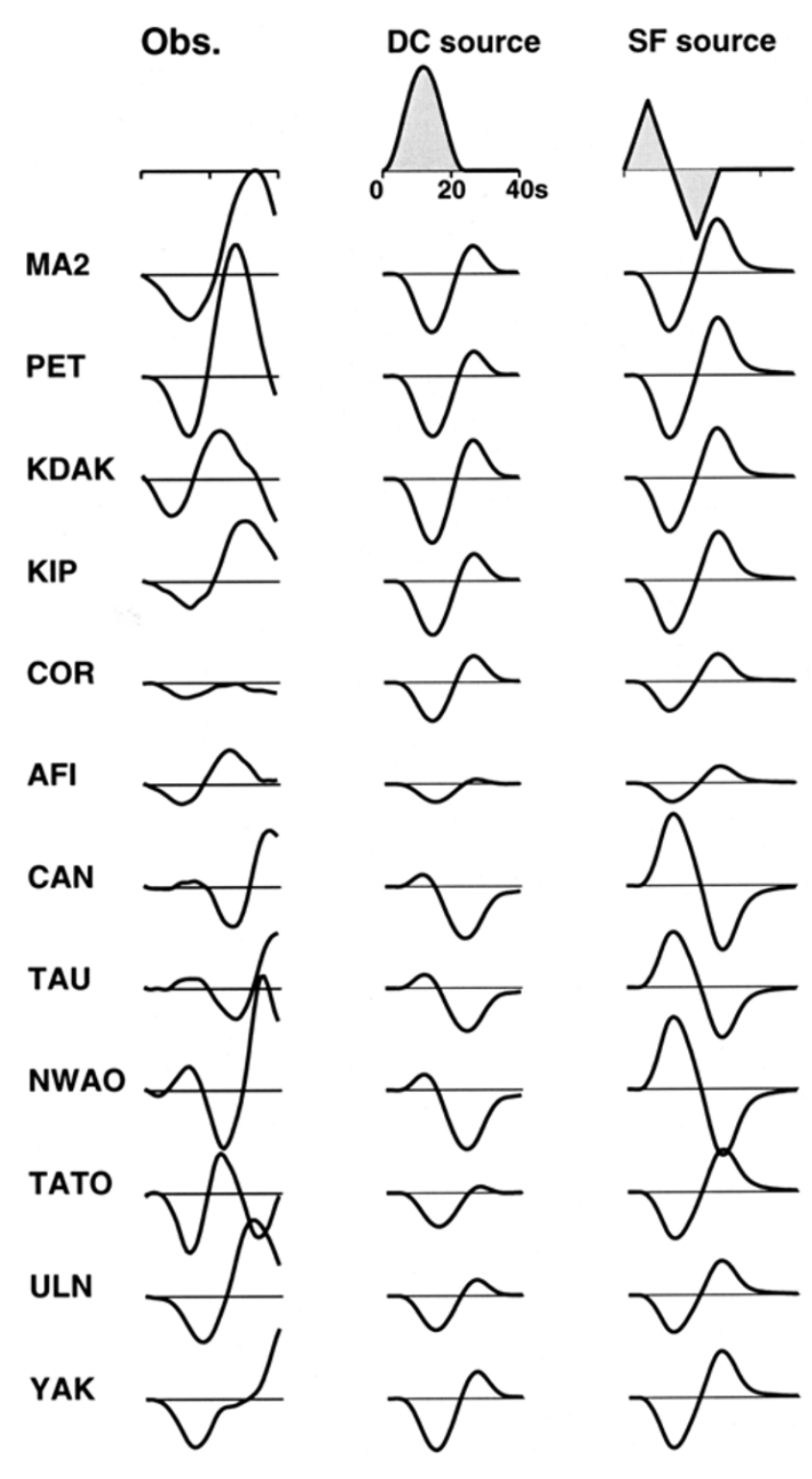

Fig. 7. Comparison of radial S waves. Left column: observed records; central column: synthetic records for a buried double-couple; right column: synthetic records for a single force at free surface. Waveform fit (especially at southern stations: CAN, TAU, and NWAO) suggests that a buried double-couple source is preferred to a free-surface single-force. in the same wave shape regardless the station azimuth. On the contrary, a buried double-couple source accompanies delayed free surface reflections $(\mathrm{pP}, \mathrm{sP}, \mathrm{sS})$ which can result in the variation of wave shape with respect to the ray direction.

Taking these into account, we compare the observed and synthetic records of radial S-waves in Fig. 7. The first column shows the observed waveforms, the second column the synthetic waveforms for a buried double-couple (strike, dip, rake $=301^{\circ}, 86^{\circ}, 91^{\circ}$ ), and the third column for a surface single-force (azimuth $=198^{\circ}$, dip $=10^{\circ}$ upward). Since radial S-waves are sensitive to underground structures as to be easily distorted by P-SV conversion, we here restrict ourselves only to an initial portion of $S$ arrival. In Fig. 7, the opposite polarity between $\mathrm{S}$ and $\mathrm{sS}$ is seen to distort the waveforms observed at southern stations: CAN, TAU and NWAO. Such a feature is well reconstructed by a buried double-couple source but not by a free surface source. Thus the present earthquake is not likely to be modeled by a single force at free surface.

In summary, the seismic source of the 1998 PNG earthquake is well represented by a high-angle dip-slip fault which could be partly responsible for a large tsunami. However our analysis does not exclude the possibility that an aseismic submarine landslide as proposed by Imamura (1999) could be locally induced by strong ground motions either by the main shock or by a large aftershock. This could lead to a local massive tsunami.

Acknowledgments. We thank Ichiro Nakanishi and an anonymous reviewer for their useful comments. This research was partially supported by the Grant-in-Aid for Scientific Research No. 10640399 from the Ministry of Education, Japan.

\section{References}

Abe, K., Size of great earthquakes of 1837-1974 inferred from tsunami data, J. Geophys. Res., 84, 1561-1568, 1979.

Abe, K., Quantification of major earthquake tsunamis of the Japan Sea, Phys. Earth Planet. Inter., 38, 214-223, 1985.

Abe, K., Quantification of tsunamigenic earthquakes by the $M t$ scale, Tectonophys., 166, 27-34, 1989.

Bouchon, M., A simple method to calculate Green's function for elastic layered media, Bull. Seism. Soc. Am., 71, 959-971, 1981.

Ekstrom, G. and E. R. Engdahl, Earthquake source parameters and stress distribution in the Adak Island region of the Central Aleutian Islands, Alaska, J. Geophys. Res., 94, 15499-15519, 1989.

Furumoto, M. and I. Nakanishi, Source times and scaling relations of large earthquakes, J. Geophys. Res., 88, 2191-2198, 1983.

Hasegawa, H. S. and H. Kanamori, Source mechanism of the magnitude 7.2 Grand Banks earthquake of November 1929: Double couple or submarine landslide?, Bull. Seism. Soc. Am., 77, 1984-2004, 1987.

Hurukawa, N., A fault plane of the 1998 Papua New Guinea earthquake estimated from relocated aftershocks using data of the International Data Center of CTBT, Zisin, 52, 95-99, 1999 (in Japanese).

Imamura, F., Sissano, Papua New Guinea tsunami earthquake, Zisin Journal, 27, 8-17, 1999 (in Japanese).

Kanamori, H. and D. L. Anderson, Theoretical basis of some empirical relations in seismology, Bull. Seism. Soc. Am., 65, 1073-1095, 1975.

Kanamori, H. and M. Kikuchi, The 1992 Nicaragua earthquake: a slow tsunami earthquake associated with subducted sediments, Nature, 361, 714-716, 1993.

Kawata, Y., B. C. Benson, J. C. Borrero, J. L. Borrero, H. L. Davies, W. P. de Lange, F. Imamura, H. Letz, J. Nott, and C. E. Synolakis, Tsunami in Papua New Guinea was as intense as first thought, EOS, 80, 103-105, 1999.

Kikuchi, M. and H. Kanamori, Source characteristics of the 1992 Nicaragua tsunami earthquake inferred from teleseismic body waves, $P A G E O P H$, 144, 441-453, 1995. 
Morita, Y., OHMS (Ocean Hemisphere project, Mobile Seismic observation system), in OHP International Symposium, Chiba, 11/6-8, 74-75, 1997.

Tanioka, Y., Analysis of the 1998 PNG earthquake using tsunami waveforms observed in Japan, Programme and Abstracts of Seism. Soc. Japan 1998 , Fall Meeting, C61, 1998 (in Japanese).

Tanioka, Y. and K. Satake, Fault parameters of the 1986 Sanriku tsunami earthquake estimated by tsunami numerical modeling, Geophys. Res. Lett., 23, 1549-1552, 1996.

M. Kikuchi (e-mail: kikuchi@eri.u-tokyo.ac.jp), Y. Yamanaka, K. Abe, and Y. Morita 